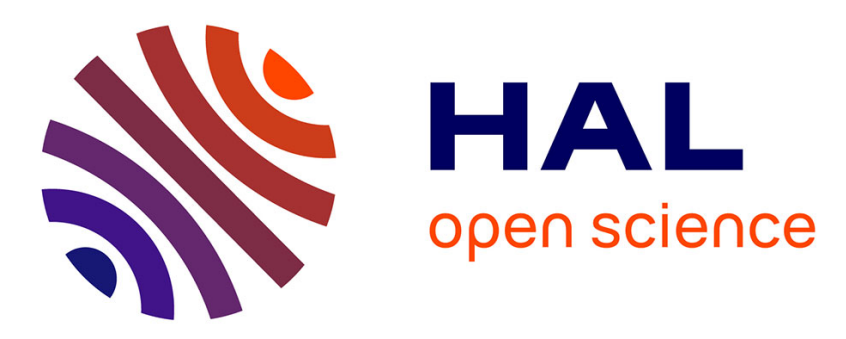

\title{
A New Hemodynamic Ex Vivo Model for Medical Devices Assessment
}

\author{
Blandine Maurel, Christophe Sarraf, Farid Bakir, Feng Chai, Mickael Maton, \\ Jonathan Sobocinski, Adrien Hertault, Nicolas Blanchemain, Stephan Haulon, \\ Patrick Lermusiaux
}

\section{To cite this version:}

Blandine Maurel, Christophe Sarraf, Farid Bakir, Feng Chai, Mickael Maton, et al.. A New Hemodynamic Ex Vivo Model for Medical Devices Assessment. Annals of Vascular Surgery, 2015, 29 (8), pp.1648-1655. 10.1016/j.avsg.2015.06.066 . hal-02444677

\section{HAL Id: hal-02444677 https://hal.science/hal-02444677}

Submitted on 18 Jan 2020

HAL is a multi-disciplinary open access archive for the deposit and dissemination of scientific research documents, whether they are published or not. The documents may come from teaching and research institutions in France or abroad, or from public or private research centers.
L'archive ouverte pluridisciplinaire HAL, est destinée au dépôt et à la diffusion de documents scientifiques de niveau recherche, publiés ou non, émanant des établissements d'enseignement et de recherche français ou étrangers, des laboratoires publics ou privés. 


\section{A New Hemodynamic Ex Vivo Model of Drug Eluting Stent Assessment}

Blandine Maurel ${ }^{1,2}$, Christophe Sarraf ${ }^{3}$, Farid Bakir ${ }^{3}$, Feng Chai ${ }^{2}$, Mickael Maton ${ }^{2}$, Jonathan Sobocinski ${ }^{1,2}$, Adrien Hertault ${ }^{1,2}$ Nicolas Blanchemain ${ }^{2}$, Stephan Haulon ${ }^{1,2}$, Patrick Lermusiaux ${ }^{4}$.

${ }^{1}$ Service de Chirurgie Vasculaire, Hôpital Cardiologique, CHRU Lille, France

${ }^{2}$ Groupe Recherche Biomatériaux, INSERM U1008, Université Lille 2, France

${ }^{3}$ Laboratoire DynFluid, Ecole Nationale Supérieure des Arts et Métiers ParisTech, Paris, France

${ }^{4}$ Service de Chirurgie Vasculaire, Groupement Hospitalier Edouard Herriot, CHU Lyon, Faculté de médecine Lyon 1, Université Claude Bernard- LYON 1, France

Corresponding author :

Dr Blandine Maurel

Chirurgie Vasculaire

Hôpital Cardiologique, CHRU de Lille

59037 Lille Cedex, France

Tel: + 33320445005

maurel.blandine@yahoo.fr

blandine.maurel@chru-lille.fr 


\section{ABSTRACT}

Introduction: In stent restenosis (ISR) remains a major public health concern with an increased morbidity, mortality and health-related costs. Drug-eluting stents (DES) have reduced ISR, but are associated with healing-related issues or hypersensitivity reactions, leading to an increased risk of late acute stent thrombosis. Evaluations of new DES are based on animal models or in vitro release systems which show several limitations. The role of flow and shear stress on endothelial cell and ISR has also been emphasized. The aim of this work was to design and first evaluate an original bioreactor, reproducing ex vivo hemodynamic and biological conditions similar to human conditions, to further evaluate new DES.

Methods \& Results: This bioreactor was designed to study up to 6 stented arteries connected in bypass, immersed in a culture box, in which circulated a physiological systolo-diastolic resistive flow. Two centrifugal pumps drove the flow. The principal pump generated pulsating flows by modulation of rotation velocity, and the second pump worked at constant rotation velocity, ensuring the counter pressure levels and backflows. The flow rate, the velocity profile, the arterial pressure and the resistance of the flow were adjustable. The bioreactor was placed in an incubator to reproduce a biological environment. A first experience of feasibility was realized over a period of 24 days. Three rat aortic thoracic arteries were placed into the bioreactor, immersed in cell culture medium change every 3 days, and with a circulating systole diastolic flux circulating among the entire experimentation. There was no infection, no leak. At the end of experimentation, a morphometric analysis was performed confirming the viability of the arteries. Conclusion: We design and patent an original hemodynamic ex vivo model to further study new DES and ISR. We will next validate this ex vivo model of ISR reproducing this experimentation with stented arteries. Once validated, this bioreactor will allow characterization of the velocity field and drug transfers within a stented artery with new functionalized DES, with experimental means not available in vivo. Another main point will be the reduction of animal experimentation, and the availability of first results of new DES in human tissues (human infra popliteal or coronary arteries collected during human donation). 


\section{INTRODUCTION}

Percutaneous interventions with stent implantation are now well recognized as the treatment of choice for dilation of flow-limiting coronary and peripheral atherosclerotic stenosis. However, there are drawbacks to coronary or peripheral stenting, with in stent restenosis (ISR) being the Achilles' heel, accounting for a rate of failure up to 15 to $25 \%$ at 6 month for coronary pathology ${ }^{1}$, and up to $50 \%$ in infrapopliteal arteries ${ }^{2,3}$. ISR is a chronic mechanism related to an excessive healing of the arterial wall after stent implantation, considered to be a response to traumatic injury. It is essentially due to vascular smooth muscle cell (VSMC) proliferation and migration, and excessive extracellular matrix production, leading to excessive neointima formation involving a recurrence of the symptoms and a new intervention for the patient ${ }^{4}$.

Drug-eluting stents (DES) have revolutionized the field of percutaneous coronary interventions by reducing restenosis rates to less than $10 \%$, DES systems combine mechanical and pharmacological approaches, by releasing locally highly cytotoxic (paclitaxel) or cytostatic (sirolimus or rapamycin) drugs via a permanent polymer. However, their use causes a delay of healing of the vessel wall associated with impairment of the endothelium function and hypersensitivity reactions induced by polymers that increases the risk of late acute stent thrombosis $^{7}$. Despite a decrease of reintervention for ISR observed, morbidity and mortality are not significantly reduced by the employment of the first generation of $\mathrm{DES}^{8}$. Recently, a new generation of DES integrating adsorbable polymers (PLLA) and less toxic drugs (everolimus, biolimus, etc..) appears. Clinical trials have demonstrated that the second-generation DES is superior to the first-generation in terms of safety and efficacy ${ }^{9}$. Nevertheless, vascular responses to theses stents remain unclear and long term safety of their utilisation is still under investigation $^{10}$. Thus, ISR and late acute thrombosis following stent implantation remain frequent clinical and societal concerns and are therefore under extensive investigation.

Currently, evaluations of DES are based on animal models or in vitro release systems which show several limitations. Animal models of stenting probably predict human responses but the temporal response to healing is characteristically different, as it's substantially prolonged in 
humans ${ }^{11}$. For instance, the inability to perform regular tissue and blood samples in vivo makes very difficult the evaluation of the drug release, the tissue distribution, and the degradation of the polymer. Moreover, the role of the flow on endothelial cell, on the drug elution and on the reendothelialisation has been emphasized. Low or high wall shear stresses play a main role in the development of atherosclerotic plaque and arterial remodeling ${ }^{12}$, and the altered hemodynamics with abnormal shear stresses on endothelial cells, generated by the stent presence, is an important stimulus to $\mathrm{ISR}^{13}$.

From our knowledge, any ex vivo model is currently available to evaluate coated stent efficiency in near physiological human conditions. Therefore, the original development of an ex vivo bioreactor to do it, will be undoubtedly a real tool for researchers and for all vascular companies marketing DES. The goal of this bioreactor is to allow characterization of the velocity field, drug release kinetic and the polymer degradation within stented arteries with DES, with experimental means not available in vivo. It will also reduce animal experimentation and will provide first results in human arteries (infra-popliteal or coronary arteries collected during human donation and used in the bioreactor after stenting).

The aim of this work was to design and first evaluate the feasibility of an original bioreactor, reproducing ex vivo hemodynamic (resistive systolo-diastolic flow) and biological conditions similar to human conditions.

\section{MATERIAL AND METHODS}

\section{Design of the bioreactor}

The bioreactor was designed to generate various pulsatile flows in a large range of biological conditions, with a physiological resistive systolo-diastolic flow circulating simultaneously in up to 6 arteries. The flow rate, the velocity profile, the arterial pressure and the resistance of the flow can be settled according to the type of artery studied (coronary arteries or infra-popliteal arteries) or according to the physiological conditions (hypertension...).

\subsection{Schematic circuit of the bioreactor}


The hydraulic circuit is presented schematically figure 1. Its originality lied in two centrifugal pumps which drove the flow. The principal pump (1) generated pulsating flows by modulation of rotation velocity. Its inlet was connected to a reservoir of liquid (3). The arteries were placed in a culture box (4). The reservoir and the culture box (4) were not sealed to enable gas exchanges with the environment. It is known that a centrifugal pump only works following its own characteristic of pressure versus flow rate ${ }^{14}$. Since the flow to settle depends on the arteries studied, the pump could produce excess of fluid which was bypassed to the reservoir by a diverter (7). The second pump (2), worked at constant rotation velocity, ensuring the counter pressure levels and backflows if they are desired. In particular cases (coronary arteries) the second pump was not compulsory and the valve (8) was sufficient to set the impedance of the circuit.

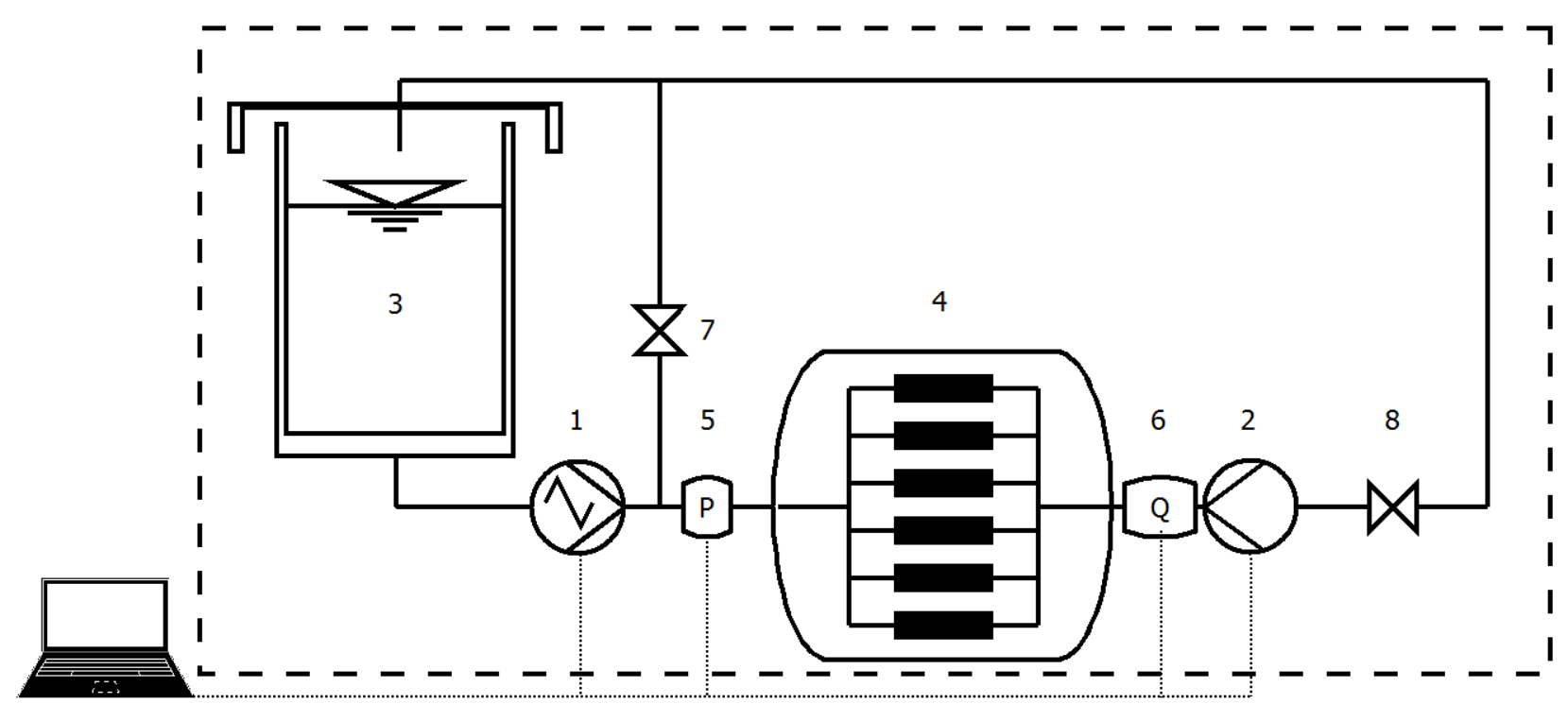

Figure 1: Schematic of the bioreactor. 1- Pulsatile pump. 2- Static counter pressure pump. 3Reservoir. 4- Stented arteries in a culture box. 5- Pressure transducer. 6- Flow rate transducer. 7Bypass valve. 8- Counter pressure valve.

\subsection{Non-dimensional characteristics of the pump}

The non-dimensional characteristics of the pump are shown in Fig. 2a. The flow-rate coefficient $(\Phi)$ and pressure rise coefficient $(\Psi)$ were defined respectively by equations 1 and 2 . The volumetric flow rate is $q v, \omega$ the rotational velocity, $R_{\text {ext }}$ the diameter of the rotor of the pump, $\Delta p$ the rise of pressure between inlet and outlet and $\rho$ the density of the fluid. In this equations, a variation of $\omega$ produce a variation in $\mathrm{qv}$ and $\Delta \mathrm{p}$. The principle of the system was to set the 
appropriate law of $\omega(\mathrm{t})$ to produce the law of $\Delta \mathrm{p}(\mathrm{t})$. The driving of the pump was ensuring by a brushed DC permanent magnet motor. The basic equations of this motor are $\mathrm{U}=\mathrm{E}+\mathrm{rI}, \mathrm{E}=\mathrm{Ke}^{*} \omega$ and $\mathrm{I}=\mathrm{Kc} * \mathrm{C}$ where $\mathrm{U}$ is the supply voltage, $\mathrm{E}$ the electromotive force, $\mathrm{r}$ the internal resistivity, $\mathrm{I}$ the current intensity, C the torque, specific Ke and Kc constants. To change $\omega$, it was necessary to modify $\mathrm{E}$ and therefore the supply voltage $\mathrm{U}$. Figure $2 \mathrm{~b}$ shows that the shape of the pressure function produced by the pump was almost similar to the tension $\mathrm{U}(\mathrm{t})$ imposed to the motor. It was then relatively straightforward to set the pressure parameters of the essay using a black-box approach modifying the shape, the aspect ratio, the offset of the tension command. To obtain the flow rates observed in a body, the impedance of the arteries circuit was set by counter pressure devices (a secondary pump and a valve).

$$
\Phi=\frac{q_{v}}{\pi \omega R_{e x t}^{\mathbf{z}}}(1), \quad \boldsymbol{\Psi}=\frac{\Delta p / \rho}{\omega^{\mathbf{2}} R_{e x t}^{\mathbf{z}}}(2),
$$

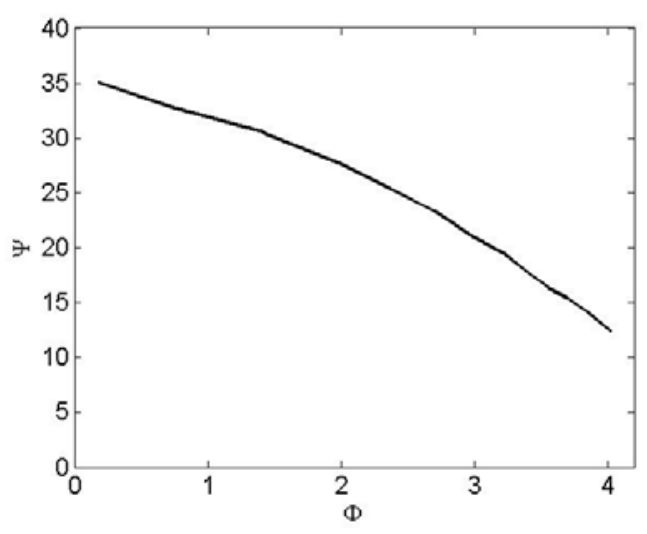

Figure 2a: Centrifugal Pumps caracteristic. Pressure rise coefficient $\Phi$ vs. flow-rate coefficient $\Psi$

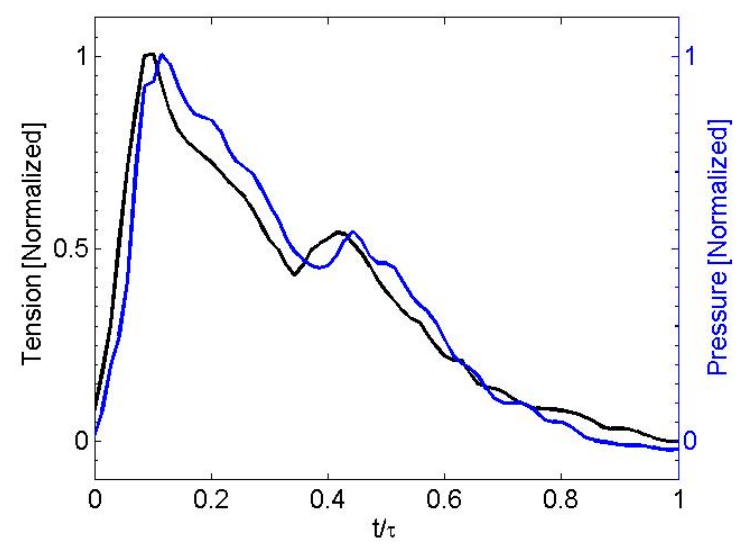

Figure 2b: Law of the tension motor supply and law of the pressure over time at the outlet of the pump.

\subsection{Flow Conditions}

The flow conditions were monitored by a pressure transducer JUMO MIDAS SI 401006 and a turbine flow rate sensor Gems FT-110, respectively upstream and downstream the arteries. This setup was placed in an incubator. The biological sustainabilyty of the transducers was tested with success. However the flow rate transducer was not employed in his fully metrological range, more specially when a zero flow rate was set in diaslole part of the cycle. In this conditions, the 
mean flow rate given by the transucer after integration of the signal was compared with series of volumetric measurements over 100 cycles. The maximum discrepency reaches 3\%.

\section{Biological experimentation}

\subsection{Ex vivo assay}

All animal experiments were performed by a single operator and all study protocols were approved by our local Institutional Animal Care and Use Committee (NCEEA 212011).

Three adult male Wistar rats (350 to 400g, Charles River, France) were anesthetized (ketamine $130 \mathrm{mg} / \mathrm{kg}$ and xylazine $14 \mathrm{mg} / \mathrm{kg}$ intraperitoneally) and a sternotomy was performed. The

descending aorta was controlled and intercostal arteries were individually ligated with 8/0 sutures. The thoracic aorta arteries were removed, gently rinsed with saline. Under a laminar flow hood, arteries were immersed in culture medium (blending of Smooth Muscle Cell Growth Medium and Endothelial Cell Growth Medium (PromoCell GmbH, Heidelberg, Germany), supplemented with penicillin-streptomycin $(50 \mathrm{UI} / \mathrm{mL}))$ and connected in bypass in the bioreactor. Once the arteries connected, Smooth Muscle Cell Growth Medium (PromoCell GmbH, Heidelberg, Germany) with $40 \%$ of glycerol to reproduce the blood viscosity ${ }^{15}$, supplemented with penicillin-streptomycin $(50 \mathrm{UI} / \mathrm{mL})$ was put into circulation in the circuit, according to established resistive systolo-diastolic flow. The bioreactor was placed in an incubator, in $37^{\circ} \mathrm{C}$ and in a $5 \% \mathrm{CO}_{2} / 95 \%$ air atmosphere. The culture medium was replaced every 3 days under the laminar flow hood, thanks to a detachable cell culture flask. After 24 days of experimentation, the arteries were removed and proceed for histomorphological analysis.

\subsection{Histomorphological analysis}

Similarly to the procedure previously described ${ }^{16}$, arteries were fixed in $4 \%$ paraformaldehyde phosphate-buffered solution, dehydrated, and embedded in methylmethacrylate polymer (Technovit 9100 new, Heraeus, Germany). Sections 60 $\mu$ m thick were cut along the entire embedded vessels. Sections were stained with Mayer hematoxylin and eosin, mounted on a glass slide and examined under light microscopy (Leika DMIL, Germany) with magnificence of $\times 5$. Images were digitized and recorded with the use of a video camera (AxioCam ERc 5s, Carl Zeiss Microscopy, Germany). For each vessel, 10 sections along the entire length were randomly 
chosen for a histo-morphometric analysis, performed with a computerized digital microscopic planimetry algorithm (bioquant program).

\section{RESULTS}

\subsection{Mechanical feasibility}

All the circuit was built out of biologically compatible materials saying PMMA or equivalent, silicon rubbers and stainless steel components. The biological sustainability was tested with success over 24 days. Figure3 shows some details of the realization of the pump, the reservoir, the arteries connected and the culture box.

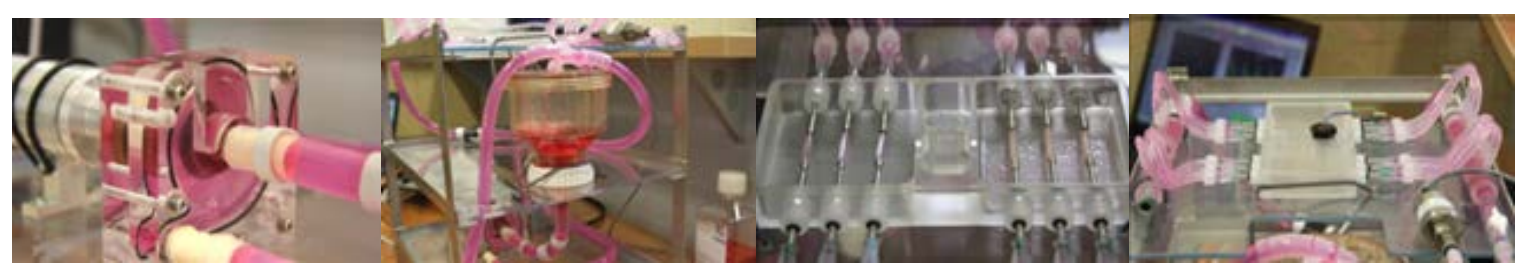

Figure 3: Bioreactor with polymeric arteries. A: centrifugal pump; B: circulating fluid reservoir allowing changes in flow; C: Container of tissue culture with 6 arteries connected in derivation; D: Tissue culture container and its lid with the anti-overflow system to stop the pump in case of leak.

\subsection{Hemodynamic measurements}

For detailed hemodynamic measurements, the bioreactor was fited with three constant circular tube section of silicone rubber of internal diameter $\mathrm{D}=2.2 \mathrm{~mm}$. The fluid was Newtonian as considered for blood in this case of diameter ${ }^{17}$. The medium was mixed with $40 \%$ of glycerol to reproduce the blood viscosity of $\mu=3,5 \mathrm{mPa}$.s at body temperature and density $\rho=1050 \mathrm{~kg} . \mathrm{m}^{-3}$. An example of pulsating flow conditions used for validation is detailed in Table 1 . The mean flow rate $\mathrm{qv}_{\max }$ was given in milliliters per minute $(\mathrm{ml} / \mathrm{min})$; $\mathrm{V}_{\max }$ was the maximum velocity in centimeters per second $(\mathrm{cm} / \mathrm{s})$. The Reynolds number, Re representing the ratio of inertial to forces to viscous forces was given by: $\operatorname{Re}=\rho \mathrm{V}_{\text {max. }} D \mu^{-1}$. The Womersley number, $\alpha$, expressed the pulsating flow frequency in relation to viscous effects; it was defined by $\alpha=\mathrm{R}\left(\Omega \rho \mu^{-1}\right)^{0.5}$, where $\mathrm{R}$ is the artery radius in $\mathrm{m}$, and $\Omega$ the pulsation frequency of the flow in rad.s ${ }^{-1}$. A representative cycle of intra-arterial flow-rate and operating pressure is given in Figure 4. The 
measured confirmed the standard velocity characteristics of the flow, and particularly, a resistive flow as describe in human muscular arteries (zero-flow imposed during a part of diastole) ${ }^{18}$.

\begin{tabular}{lcc}
\hline parameters & value & unit \\
\hline $\mathbf{D}$ & 2.2 & $\mathrm{~mm}$ \\
$\Delta \mathbf{p}$ min/max & $85-130$ & $\mathrm{mmHg}$ \\
$\mathbf{q v}$ & $0-110$ & $\mathrm{ml} / \mathrm{min}$ \\
$\mathbf{V} \_\mathbf{m a x}$ & $0-48$ & $\mathrm{~cm} / \mathrm{s}$ \\
$\boldsymbol{\mu}$ & 3.5 & $\mathrm{~N} . \mathrm{s} . \mathrm{m}^{-2}$ \\
$\mathbf{R e}$ & 320 & - \\
$\mathbf{f}$ & 70 & Cycle/s \\
$\boldsymbol{\alpha}$ & 1.63 & -
\end{tabular}

Table 1: flow conditions in feasibility testing. D: internal diameter; p: pressure; qv: mean flow rate; Vmax: maximum velocity; $\mu$ : blood viscosity; Re: Reynolds number; f: frequencies ; $\alpha$ : Womersley number;

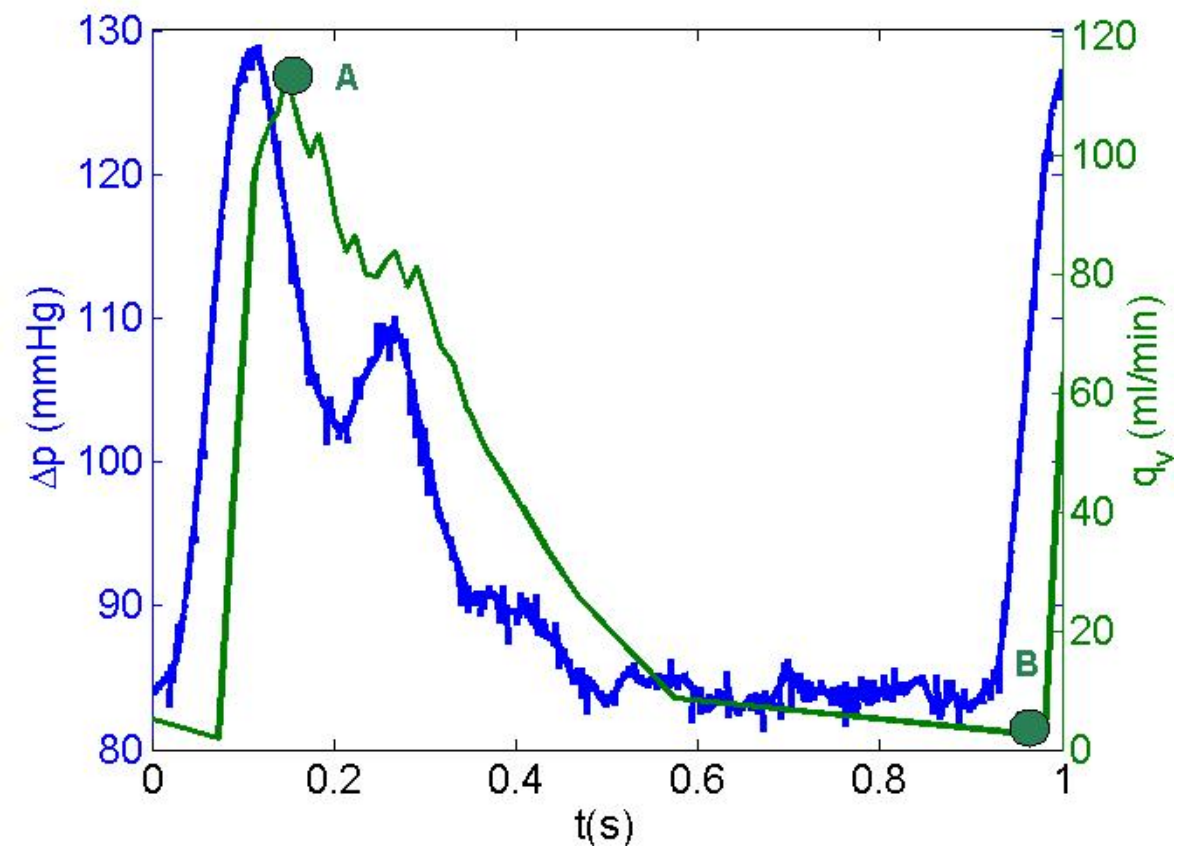

Figure 4: Pressure at the inlet and Flow at the outlet of arteries over time; point A: peak systolic flow; point B: flow at the end of diastole, a zero-flow imposed in condition of a muscular human leg artery. 


\subsection{Biological evaluation}

The bioreactor, with the 3 rat aorta branched in a bridged tap, has been functional during the experimentation (24 days). A systolo diastolic flux, with a systolic arterial pressure of $100 \mathrm{mmHg}$ and a diastolic arterial pressure of $60 \mathrm{mmHg}$, has circulated in the bioreactor during the 24 days. There was no leak and no bacterial infection in the bioreactor. The histomorphological analysis of the arteries showed no evidence of abnormality or infection. (Figure 5).

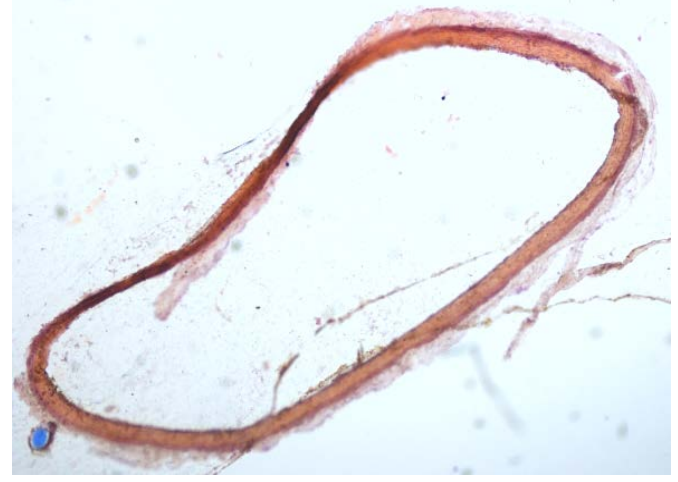

Figure 5: morphological analysis of a rat aorta section, removed after 24 days in the bioreactor.

\section{DISCUSSION}

We elaborated and patent ${ }^{19}$ an ex-vivo bioreactor, to study stented arteries with drug eluting stent during a prolonged period, in biological and hemodynamical conditions close to those of life. We demonstrated that we reproduced a resistive systolo-diastolic flux in the circuit, similar to those of peripheral muscular arteries. The attractive feature of this system is based on the possibility to control and adjusts the bioreactor conditions on demand to match the type of arteries conditions. We also demonstrated in this work the feasibility of this experimentation, by maintaining arteries alive in the bioreactor during 24 days without tissue infection.

Ex vivo engineering of living tissues is a rapidly developing area with the potential to impact significantly on a wide-range of biomedical applications. By enabling reproducible and controlled changes of specific environmental factors, bioreactor systems provide both the technological means to reveal fundamental mechanisms of cell function in a 3D environment, and the potential to improve the quality of engineered tissues ${ }^{20}$. 
The aim of our original bioreactor is to overcome the drawbacks of animal models to study ISR and DES. Animal models of stenting probably predict human responses, as the stages of healing are similar, but the temporal response to healing is characteristically different, and is substantially prolonged in humans. One obvious explanation for this is the underlying atherosclerotic process in human. The absence of atherosclerotic disease is likely to contribute to a more predictable healing response in animals. In contrast, in diseased human coronary arteries, at least $70 \%$ of the stent is in direct contact with the underlying atherosclerotic plaque. Furthermore, rather than a simple proliferative response, smooth muscle cell migration from within the plaque or media to the expanding neointima may be the more dominant in human ${ }^{11}$. In our bioreactor, human arterial tissue will be used to assess the new DES and obtain first results of efficiency in human.

Another weakness of the animal models is the inability to perform regular tissue and blood samples that makes very difficult the evaluation of kinetic characteristics of drug eluting stent (kinetic of the drug release, tissue distribution of drug and degradation of the polymer). Our bioreactor allows performing a detailed characterization of the drug transfers within a stented artery with DES. The associated velocity fields as well the shear stresses are easy to reach. At least, animal experimentation is ethically controversial and must be limited to minimum.

To our knowledge, only a static ex vivo model of ISR has been described in literature. It consists on internal mammary arteries from atherosclerotic patients stented and maintained in culture for 0-28 days ${ }^{21}$. Nevertheless, Samady et al ${ }^{12}$ emphasized the major role of biomechanical factors and wall shear stress (WSS) to human coronary atherosclerotic plaque progression and transformation. They demonstrated that coronary segments with low WSS in patients with coronary arterial disease developed greater plaque area progression over a relatively short time interval (6 months) compared with segments located in areas with intermediate and high WSS. Compared with intermediate-WSS segments, low-WSS segments developed progression of plaque and necrotic core area, whereas high-WSS segments had progression of necrotic core and dense calcium and regression of fibrous and fibro fatty tissue. In vitro and animal studies have also demonstrated that low WSS promotes atherosclerosis development through loss of the physiological flow-oriented alignment of the endothelial cells, increasing low-density lipoprotein accumulation, proliferation of smooth muscle cells, transmigration of macrophages, and 
inflammation; impairing nitric oxide-dependent atheroprotection; and promoting oxidative stress $^{22,23}$. Nonlaminar shear stress, such as might be present after vessel injury like stenting, results in ERK1/2 activation from both PDGF-BB and interleukin-1, and results in SMC chemotaxis and proliferation ${ }^{24,25}$. Moreover, in our experience with static culture of stented human infra-popliteal arteries, no ISR was depicted (personal data unpublished). Thus a static model of ISR seems inappropriate.

Two other bioreactors are patented. One model is design for ex vivo hemodynamic assessment of wall shear stress after stenting ${ }^{26}$. It reproduces a sinusoidal flux during short experimentations. The other model is design for the assessment of drug scattering ${ }^{27}$. It contains a peristaltic pump and several benches. Our bioreactor is designed for the assessment of drug scattering and efficacy in biological tissues during long term experimentations. The circulating flux is a resistive systolodiastolic flux, more similar to the one in infrapopliteal arteries. Our bioreactor will lead to a better understanding of the relationship between ISR and shear stress then providing a convenient tool for the ex-vivo evaluation of the efficacy of DES.

\section{Limitations}

These are first results evaluating our bioreactor. Currently we only demonstrated the feasibility of hemodynamic simulation of arterial resistive blood flow, and the proper functioning of the bioreactor in biological conditions. Further investigations are required to assess the reproduction of in stent restenosis ex vivo.

\section{Conclusions}

We developed, patent and first evaluate an original hemodynamic ex vivo model to assess in stent restenosis and new drug eluting stents. Further investigations are requires to demonstrate the ex vivo reproduction of in stent restenosis. This bioreactor will be a tool of work for researchers and companies manufacturing stents and particularly drug eluting stents. Indeed, the latter will be used to predict drug release kinetics, to evaluate the relevance and the stability of the polymer coating, and to investigate the tissue integration or the therapeutic activity of the coated stents on in stent restenosis. Finally, the originality and the added value of this bioreactor consist in working with human arteries that ultimately will reduce the animal assays. 


\section{Funding source}

The French Society of Vascular Surgery provided financial support for the conduct of the research through a research grant.

\section{Acknowledgements}

The authors thanks the professionals of the hemodynamic departement of the Hospital Centre of

Lille, France, for their contribution to the design of the bioreactor.

\section{Bibliography}

1. Mukherjee D, Moliterno DJ. Effectiveness of drug-eluting stents in real-world patients. JAMA : the journal of the American Medical Association 2008;299:454-5.

2. Lejay A, Georg Y, Bajcz C, et al. Endovascular treatment of infra-popliteal arteries in patients with critical limb ischemia. Acta chirurgica Belgica 2009;109:684-93.

3. Katsanos K, Diamantopoulos A, Spiliopoulos S, Karnabatidis D, Siablis D. Below-the-ankle angioplasty and stenting for limb salvage: anatomical considerations and long-term outcomes. Cardiovascular and interventional radiology 2013;36:926-35.

4. Farb A, Weber DK, Kolodgie FD, Burke AP, Virmani R. Morphological predictors of restenosis after coronary stenting in humans. Circulation 2002;105:2974-80.

5. Sousa JE, Costa MA, Sousa AG, et al. Two-year angiographic and intravascular ultrasound followup after implantation of sirolimus-eluting stents in human coronary arteries. Circulation 2003;107:381-3.

6. Stone GW, Ellis SG, Cox DA, et al. A polymer-based, paclitaxel-eluting stent in patients with coronary artery disease. The New England journal of medicine 2004;350:221-31.

7. Joner M, Finn AV, Farb A, et al. Pathology of drug-eluting stents in humans: delayed healing and late thrombotic risk. Journal of the American College of Cardiology 2006;48:193-202.

8. Kastrati A, Mehilli J, Pache J, et al. Analysis of 14 trials comparing sirolimus-eluting stents with bare-metal stents. The New England journal of medicine 2007;356:1030-9.

9. Bangalore $\mathrm{S}$, Kumar $\mathrm{S}$, Fusaro $\mathrm{M}$, et al. Short- and long-term outcomes with drug-eluting and bare-metal coronary stents: a mixed-treatment comparison analysis of 117762 patient-years of followup from randomized trials. Circulation 2012;125:2873-91.

10. Otsuka F, Vorpahl M, Nakano M, et al. Pathology of second-generation everolimus-eluting stents versus first-generation sirolimus- and paclitaxel-eluting stents in humans. Circulation 2014;129:211-23.

11. Virmani R, Kolodgie FD, Farb A, Lafont A. Drug eluting stents: are human and animal studies comparable? Heart 2003;89:133-8.

12. Samady H, Eshtehardi P, McDaniel MC, et al. Coronary artery wall shear stress is associated with progression and transformation of atherosclerotic plaque and arterial remodeling in patients with coronary artery disease. Circulation 2011;124:779-88. 
13. Chiastra C, Migliavacca F, Martinez MA, Malve M. On the necessity of modelling fluid-structure interaction for stented coronary arteries. Journal of the mechanical behavior of biomedical materials 2014;34:217-30.

14. R C. Mécanique expérimentale des fluides: Dynamique des fluides réels. . In: Masson, ed. Turbomachines1994.

15. Han SI, Marseille O, Gehlen C, Blumich B. Rheology of blood by NMR. Journal of magnetic resonance 2001;152:87-94.

16. Heleen M. M. van Beusekom M, PhD, Deirdre M. Whelan, BSc, Monique van de Plas, MD, and Willem J. van der Giessen, PhD. A practical and rapid method of histological processing for examination of coronary arteries containig metallic stents. Cardiovascular Pathology 1996;5:69-76.

17. R C. Biomécanique circulatoire1984.

18. Boccalon H LP. Physiologie de la circulation artérielle. . Encycl Méd Chir (Editions Scientifiques et Médicales Elsevier SAS, Paris, tous droits réservés) 2000;Angéiologie:15p.

19. Maurel B SC, Lermusiaux P, Bakir F., inventor FR 2973146, assignee. BANC DE TEST POUR STENT. France2012.

20. Martin I, Wendt $D$, Heberer $M$. The role of bioreactors in tissue engineering. Trends in biotechnology 2004;22:80-6.

21. Guerin P, Rondeau F, Grimandi G, et al. Neointimal hyperplasia after stenting in a human mammary artery organ culture. Journal of vascular research 2004;41:46-53.

22. Malek AM, Alper SL, Izumo S. Hemodynamic shear stress and its role in atherosclerosis. JAMA : the journal of the American Medical Association 1999;282:2035-42.

23. Barakat Al, Davies PF. Mechanisms of shear stress transmission and transduction in endothelial cells. Chest 1998;114:58S-63S.

24. Dardik A, Yamashita A, Aziz F, Asada H, Sumpio BE. Shear stress-stimulated endothelial cells induce smooth muscle cell chemotaxis via platelet-derived growth factor-BB and interleukin-1alpha. J Vasc Surg 2005;41:321-31.

25. Asada H, Paszkowiak J, Teso D, et al. Sustained orbital shear stress stimulates smooth muscle cell proliferation via the extracellular signal-regulated protein kinase 1/2 pathway. J Vasc Surg 2005;42:77280.

26. ZHAO W-hZ, Jun ; YUN, Xia ; LU Bing-heng, inventor Intravascular stent structure design oriented blood flow characteristic test device. China2009.

27. WANG G-x, inventor Drug release determination device of drug-eluting intravascular stent. Republic of China2009. 